\title{
MERCANTILIZAÇÃO VERSUS FORMAÇÃO HUMANA NO ENSINO SUPERIOR: NOTAS SOBRE A PRODUÇÃO ACADÊMICA
}

Pauliane Rodrigues Resende Camila Alberto Vicente de Oliveira Layla Karoline Alves Teixeira Flores

RESUMO: Considerando a ampliação do Ensino Superior no Brasil nos últimos vinte anos e a formação integral como princípio basilar de todos os níveis educacionais, o presente artigo levanta e analisa dissertações e teses produzidas na área de Educação sobre o fenômeno da mercantilização do Ensino Superior. Por meio do estado do conhecimento realizado no Banco de teses e dissertações da CAPES, utilizando - prioritariamente - as expressões mercantilização e privatização e, diante dos dados coletados, destacam-se o número de pesquisas disponíveis no referido banco entre 1988 e outubro de 2019, a distribuição por região no país e as principais temáticas debatidas. Por fim, coteja o fenômeno da mercantilização do ensino superior aos princípios da formação humana e problematiza a necessidade de ampliação desses estudos de modo a desvelar o impacto desse processo nesse nível de ensino.

PALAVRAS-CHAVE: Ensino Superior. Mercantilização. Formação Humana. Estado do conhecimento.

\section{INTRODUÇÃo}

O desenvolvimento desse estudo se justifica em virtude da realização de pesquisas em nível de mestrado envolvendo o ensino superior. Para responder as questões de pesquisas que envolvem o ensino superior nos Planos Municipais de Educação e a inserção dos docentes iniciantes nos cursos de bacharelado e a formação pedagógica ${ }^{1}$ seria necessária a organização de uma revisão de literatura envolvendo os temas. Contudo, entendemos que seria pertinente mais do que proceder uma revisão do que havia sido produzido sobre os temas e sobre esse nível de ensino, sistematizar um processo mais acurado, nos termos de um estado do conhecimento, de modo a aprofundar um levantamento permitindo a verificação de tendências e lacunas nas pesquisas na área.

O uso desse tipo de pesquisa se utiliza da definição de Romanoswki e Ens (2006, p.39) acerca do estado do conhecimento, quando afirmam e defendem que

A realização destes balanços possibilita contribuir com a organização e análise na definição de um campo, uma área, além de indicar possíveis contribuições da pesquisa para com as rupturas sociais. A análise do campo investigativo é fundamental neste tempo de intensas mudanças associadas aos avanços crescentes da ciência e da tecnologia.

Completando a definição acima, Morosoni (2015) argumenta que - para além da revisão de literatura - essa modalidade de pesquisa

[...] é identificação, registro, categorização que levem à reflexão e síntese sobre a produção científica de uma determinada área, em um determinado espaço de tempo, congregando periódicos, teses, dissertações e livros sobre uma temática específica. (MOROSINI, 2015, p. 102. Grifos no original).

Interessa-nos na organização desse estado do conhecimento, identificar como as pesquisas se debruçam sobre um fenômeno explícito e que precisa ser desvelado por meio de uma abordagem acadêmica, qual seja: a expansão do ensino superior, especialmente aquele ofertado pelas instituições privadas de ensino, configurando-se como um processo de mercantilização desse nível de ensino. Esse processo se deu acompanhando as redefinições do modo de produção

1 Temáticas de pesquisa das autoras, respectivamente, sob orientação da terceira autora. 
capitalista e, diante disso, o ensino superior se viu instado a aderir a essa nova dinâmica. Nas palavras de Serafim (2011, p.241).

O final do século XX representou um momento de importantes transformações no sistema capitalista mundial. Acompanhando essas transformações, a educação superior passou - e ainda segue passando - por um período de redefinição das suas funções. Esta redefinição vincula-se às mudanças impostas pelo processo de globalização econômica que permeia o mundo contemporâneo. A principal redefinição se refere à orientação cada vez mais próxima das instituições de educação superior (IES) à lógica do "mercado".

Tendo por fundamento o discurso da eficiência da gestão e a produção de melhores e maiores resultados, a adesão a racionalidade de mercado começa a ser implementação das IES, sobretudo nas privadas. Algumas dessas características podem ser compartilhadas com Serafim (2011, p. 247) ao afirmar que

[...] a lógica do mercado passa a ser visto como a "mais" eficiente e eficaz, portanto, adequada às práticas institucionais e organizacionais. As IES passam, portanto, a serem cada vez mais adeptas e inseridas nessa lógica pró-mercado, pró-desburocratização, pró-sistema de avaliação utilitarista e quantitativo, pró-ranking, pró-valorização da relação IES-empresa, pró-flexibilização do trabalho [...].

Oliveira (2009) caracteriza algumas consequências da globalização para a educação e, dentre elas, a sua centralidade na formação da força de trabalho em decorrências das transformações aceleradas no mundo do trabalho, o uso de tecnologias e a sistematização de políticas educacionais similares em todo o mundo. Nesse contexto, a educação superior passa a se tornar mercadoria passando ocupar o centro do interesse do capital financeiro. Nessa linha, o autor explica

No início desta década, ao se identificar que o setor de educação superior sofreria rápida expansão, a atenção dos fundos de investimento voltou-se para essa área, ocasião em que foram constituídos os primeiros fundos de investimento exclusivamente direcionados à educação. Esses fundos têm condições de injetar altas quantias em empresas educacionais, ao mesmo tempo em que empreendem ou induzem processos de reestruturação das escolas nas quais investem, por meio da redução de custos, da racionalização administrativa, em suma, da "profissionalização" da gestão das instituições de ensino, numa perspectiva claramente empresarial. Essa perspectiva racionalizadora é fundamentalmente orientada para a maximização de lucros, chegando ao paroxismo em algumas situações. (OLIVEIRA, 2009, p. 743).

Novamente, o tema nos interessa e justifica a realização do estado do conhecimento porque a mercantilização do ensino superior se torna, portanto, o cenário desse nível de ensino para a contextualização de outros objetos de pesquisa e também porque ao transpor a educação à mercadoria, esta se afasta da compreensão da educação enquanto formação humana, nossa defesa na condição de professoras e pesquisadoras. Para Saviani e Duarte (2010, p.423), a formação humana se confunde com a promoção humana que só pode ser levada a cabo pela educação

[...] a educação, enquanto comunicação entre pessoas livres em graus diferentes de maturação humana, é promoção do homem, de parte a parte - isto é, tanto do educando como do educador. A formação humana coincide, nessa acepção, com o processo de promoção humana levado a efeito pela educação. 
Partindo dessas premissas, o estudo levantou e analisou dissertações e teses na área de Educação disponíveis no Banco de teses e dissertações da CAPES² entre 1988 (primeira publicação encontrada) e outubro de 2019 (momento que fora realizado a busca). Utilizando - prioritariamente - as expressões mercantilização e privatização destacam-se: o número de pesquisas, a distribuição por região no país e as principais temáticas debatidas. Após a apresentação dos dados, o debate teórico sobre a mercantilização do ensino superior é retomada e, o final, coteja o fenômeno da mercantilização do ensino superior aos princípios da formação humana e avança, tendo em vista a necessidade de ampliação desses estudos de modo a desvelar o impacto desse processo nesse nível de ensino.

\section{Pesquisas sobre mercantilização no ensino superior: Percurso METODOLÓGICO E DADOS LEVANTADOS}

O levantamento de dados realizado em outubro de 2019 no Banco de teses e dissertações da CAPES, utilizou-se dos seguintes termos: "Mercantilização", "Mercantilização do Ensino Superior", "Privatização" e "Privatização do Ensino Superior", sendo que em todas as buscas foram selecionados os filtros: Área de conhecimento: Educação; Área Avaliação: Educação e Nome Programa: Educação permitindo que as pesquisas localizadas dialogassem com as intenções desse estudo.

A utilização dos filtros juntamente com as palavras-chave/descritores indicados possibilitou o levantamento das teses e dissertações voltadas especificamente à educação, que inicialmente foi de 223 trabalhos, conforme descrito no quadro 01.

Quadro 01- Número de Teses e Dissertações levantadas no sítio da CAPES

\begin{tabular}{|l|c|}
\hline \multicolumn{1}{|c|}{ Termos utilizados para buscas } & Quantidade \\
\hline "Mercantilização" & 81 \\
\hline "Mercantilização do Ensino Superior" & 6 \\
\hline "Privatização" & 125 \\
\hline "Privatização do Ensino Superior" & $\mathbf{2 2 3}$ \\
\hline TOTAL & . \\
\hline
\end{tabular}

Organização: Resende, Flores e Oliveira (2019) com base no sítio da CAPES em out/2019.

Partindo da leitura dos títulos e resumos das teses e dissertações encontradas nesse primeiro momento, foi possível realizar a seleção dos trabalhos que eram relevantes à pesquisa, quais sejam: aqueles cuja temática central foi a mercantilização/ privatização do ensino superior, passando, portanto, após essa seleção, a um total de 133, sendo que 11 desses trabalhos estavam repetidos no Banco de teses e dissertações, restando, assim, 122 estudos científicos voltados a essa temática.

2 O Banco de teses e dissertações, da Coordenação de Aperfeiçoamento de Pessoal de Nível Superior (Capes), é um acervo que permite a consulta de resumos de teses e dissertações defendidas junto a programas de pós-graduação do país. Disponível em: < https://catalogodeteses.capes.gov.br/catalogo-teses/\#!/>.) 
Quadro 02- Teses e Dissertações após a primeira análise de temas

\begin{tabular}{|l|c|c|c|c|}
\hline $\begin{array}{c}\text { Termos utilizados para bus- } \\
\text { cas }\end{array}$ & Quantidade & $\begin{array}{c}\text { Outras temá- } \\
\text { ticas }\end{array}$ & $\begin{array}{c}\text { Títulos repe- } \\
\text { tidos }\end{array}$ & $\mathbf{1}^{\text {a Seleção }}$ \\
\hline $\begin{array}{l}\text { "Mercantilização" } \\
\begin{array}{l}\text { "Mercantilização do Ensino } \\
\text { Superior" }\end{array}\end{array}$ & 61 & 33 & 1 & 47 \\
\hline "Privatização" & 125 & 57 & 0 & 68 \\
\hline $\begin{array}{l}\text { "Privatização do Ensino Supe- } \\
\text { rior" }\end{array}$ & 11 & 0 & 4 & 7 \\
\hline TOTAL & 223 & 90 & 11 & $\mathbf{1 2 2}$ \\
\hline
\end{tabular}

Organização: Resende, Flores e Oliveira (2019) com base no sítio da CAPES em out/2019.

Após fazer a exclusão tanto dos trabalhos sobre temáticas diversas e títulos repetidos, foi possível chegar a um resultado de 122 pesquisas científicas, como citado, que trazem no corpo de seu título, resumo e/ou palavras-chave, as expressões "mercantilização e "privatização" e que estivessem relacionados com o ensino superior.

Ao ler os resumos dos trabalhos selecionados observamos que alguns assuntos são abordados com maior frequência, dentre eles: trabalho docente; sistema gerencialista; precarização do trabalho docente; condições, intensificação e controle do trabalho docente; predominância do setor privado nas instituições; políticas educacionais; financeirização do capital no ensino superior; programas/políticas de financiamento; transnacionalização do ensino; práticas/ políticas neoliberais; ensino para formação de mão de obra para atender o capital; desvalorização do ensino; ensino à distância; oligopólios educacionais; ensino superior como fonte rentável; monopolização do setor educacional; grupos educacionais, entre outros.

Uma análise inicial nos permite inferir que mercantilização e privatização do ensino superior têm sido objeto de estudos desde 1988 - início incipiente das políticas neoliberais no Brasil - e as temáticas apontam para o desvelamento do que se trata a transformação da educação em mercadoria no ensino superior.

Dando seguimento, objetivando identificar se houve predominância temporal nas produções foi organizado o quadro 03, para demonstrar o quantitativo anual de teses e dissertações.

Quadro 03- Número de produções - teses e dissertações - por ano

\begin{tabular}{|c|c|c|c|}
\hline ANO & DISSERTAÇÕES & TESES & TOTAL POR ANO \\
\hline 1988 & 0 & 2 & 2 \\
\hline 1993 & 1 & 0 & 1 \\
\hline 1997 & 1 & 0 & 1 \\
\hline 1998 & 1 & 1 & 2 \\
\hline 1999 & 2 & 0 & 2 \\
\hline 2000 & 1 & 1 & 2 \\
\hline 2001 & 2 & 0 & 2 \\
\hline 2002 & 4 & 1 & 5 \\
\hline 2003 & 3 & 1 & 4 \\
\hline 2004 & 2 & 0 & 2 \\
\hline
\end{tabular}




\begin{tabular}{|c|c|c|c|}
\hline 2005 & 1 & 3 & 4 \\
\hline 2006 & 3 & 1 & 4 \\
\hline 2007 & 5 & 5 & 10 \\
\hline 2008 & 8 & 3 & 11 \\
\hline 2009 & 5 & 0 & 5 \\
\hline 2010 & 1 & 2 & 3 \\
\hline 2011 & 5 & 2 & 7 \\
\hline 2012 & 2 & 1 & 3 \\
\hline 2013 & 4 & 4 & 8 \\
\hline 2014 & 5 & 3 & 8 \\
\hline 2015 & 7 & 2 & 8 \\
\hline 2016 & 5 & 3 & 9 \\
\hline 2017 & 5 & 4 & 10 \\
\hline 2018 & 7 & 3 & $\mathbf{1 2 2}$ \\
\hline TOTAL & $\mathbf{8 0}$ & $\mathbf{4 2}$ & 9 \\
\hline
\end{tabular}

Organização: Resende, Flores e Oliveira (2019) com base no sítio da CAPES em out/2019.

O quadro 03 nos permite concluir que a mercantilização e a privatização no contexto do ensino superior não são temas recentes, pois o primeiro trabalho localizado foi datado em 1988, momento esse que o ensino superior iniciava um processo de intensa expansão, devido, sobretudo, à iniciativa privada e políticas específicas para a área. De 1988 a 2018, podemos perceber a crescente busca pela temática, incidindo anual no suporte pesquisado.

Ademais, percebe-se que a busca pelo tema aumenta de forma gradativa, assim como ocorre o crescimento de instituições no país. Isso pode ser percebido ao analisarmos os números disponíveis no sítio do Instituto Nacional de Estudos e Pesquisas Educacionais Anísio Teixeira (INEP), no qual em $1995^{3}$ o Brasil tinha 894 instituições de ensino superior, e em $2018^{4}$ havia 2.448 instituições, sendo elas, púbicas, privadas, publicas-privada, Institutos Federais (IFs) e Centro Federal Tecnológica (CEFETs), ou seja, em 23 anos houve um aumento de mais 1.554 instituições, o que equivale a aproximadamente 68 instituições por ano.

Ainda, na busca de identificar se houve predominância ou estabilidade por região foi elaborado o quadro 04 .

Quadro 04- Quantidade de trabalhos por região

\begin{tabular}{|l|c|}
\hline \multicolumn{1}{|c|}{ REGIÃO } & QUANTIDADE \\
\hline Sudeste & 53 \\
\hline Sul & 27 \\
\hline Nordeste & 15 \\
\hline Centro-Oeste & 14 \\
\hline Norte & 8 \\
\hline DF & 5 \\
\hline TOTAL & $\mathbf{1 2 2}$ \\
\hline
\end{tabular}

Organização: Resende, Flores e Oliveira (2019) com base no sítio da CAPES em out/2019.

3 1995- Primeira sinopse estatística que consta no site do INEP < http://portal.inep.gov.br/web/guest/sinopses-estatisticas-da-educacao-superior>

4 2018- Última sinopse estatística que consta no site até outubro de 2019 < http://portal.inep.gov.br/web/guest/sinopses-estatisticas-da-educacao-superior> 
Ao visualizar o quadro 04, é possível perceber que a região com maior predominância sobre a temática em análise é a região Sudeste, que se destaca de forma superior as demais regiões. Para melhor visualização o Gráfico 01, abaixo, demonstra em forma de porcentagem o que cada região tem produzido sobre o assunto em destaque.

Gráfico 01- Demonstração de quantidade/porcentagem de trabalhos por Região

\section{Por'centagem de produções científicas por estado}

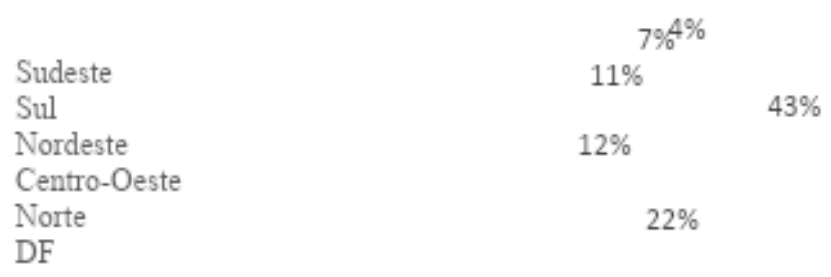

Organização: Resende, Flores e Oliveira (2019) com base em pesquisa no sítio da CAPES em out/2019

Ao analisarmos esse percentual de publicação por região é possível perceber que a Região Sudeste abrange o maior número de publicações, o que pode estar relacionado ao fato da região ser a maior afetada com o crescimento de instituições de ensino superior e por possuir o maior número de Programas de Pós-graduação. De acordo com o INEP (2018), em 1995, a Região Sudeste contava com apenas 561 instituições, já em 2018 contava com 1.121, são mais de 560 instituições em 23 anos, e isso reflete diretamente na busca por determinadas temáticas que afetam a região.

Compreende-se que esse crescimento no Ensino Superior com o incremento no número de Universidades e Faculdades no país, advém de um processo intenso de mercantilização/privatização do ensino superior, em que a política educacional brasileira buscou saídas para a crise do capital buscando transformar a formação humana no ensino superior em mercadoria e, diante disso, recuperar o lucro objetivado, avançar no processo de reestruturação produtiva e

\section{Mercantilização No ensino SUPERIOR: NOTAS SObRe POLÍtica EDUCACIONAL}

Para compreender o processo de mercantilização é necessário perceber que seu advento se deu em conformidade com o neoliberalismo, em que o Estado permitiu a abertura ao capital privado no sistema educacional brasileiro ao passo que, "as últimas décadas do século XX e o início do século XXI foram marcados por profundas mudanças no campo econômico, sociocultural, ético-político, ideológico e teórico". (FRIGOTTO e CIAVATTA, 2003, p. 01).

$\mathrm{Na}$ época, uma crise se instalou no país e a responsabilidade foi instituída ao serviço público. Nas palavras de Bresser Pereira (2001, p.13)

Uma [...] razão pela qual o novo estado é não apenas social, mas também liberal, tem a ver com a maneira pela qual se desincumbe dos serviços públicos: o novo estado tende cada vez mais a contratar externamente os serviços sociais e científicos. Isto está acontecendo devido a três razões. Por um lado, porque crescem cada vez mais as pressões no sentido da eficiência ou da redução de custos, na medida em que o tamanho desses serviços também cresce incessantemente. Por outro, porque a demanda por responsabi- 
lização política cresce proporcionalmente. E, finalmente, porque, embora a eficiência seja extremamente difícil de atingir quando o estado realiza diretamente o serviço, isso se torna relativamente mais fácil quando o serviço é contratado externamente junto a organizações sem fins lucrativos que concorrem entre si.

Assim, para o neoliberalismo, o Estado seria o responsável e culpado pela crise vivida "tanto porque gastou mais do que podia para se legitimar, já que tinha de atender às demandas da população por políticas sociais, o que provocou a crise fiscal, quanto porque, ao regulamentar a economia, atrapalhou o livre andamento do mercado". (PERONI, 2013, p. 237).

Contudo, para resolver a crise justificou-se que o serviço público é ineficiente, pois não consegue assegurar os direitos sociais, os quais são inerentes à sua função, diante disso não seria necessário prove-lo diretamente por meio do Estado, já que a preocupação deve ser com a efetividade, com a eficiência. (BRESSER PEREIRA, 2001).

Com essas alterações sofridas pelo sistema educacional brasileiro, a Lei de Diretrizes e Bases da Educação (LDB 9394/96) acabou possuindo influência mercantilista:

A regulamentação da LDB intensificou a reforma do ensino superior brasileiro, expressando a correlação entre Estado e sociedade civil num contexto de ajustes neoliberais em consonância com as orientações e acordos firmados com o Banco Mundial e o Fundo Monetário Internacional (FMI). (AGAPITO, 2016, p.125).

Nesse momento, o Estado passou a justificar-se que diante do crescimento do Ensino Fundamental e Médio, seria necessário que o Ensino Superior ficasse a cargo do setor privado. Diante disso, no Governo FHC (1995-1998), foram implantadas políticas para modernizar e gerenciar a Educação Superior. (BITTAR; RUAS, 2012).

Nessa linha, na LDB, mais precisamente em seu artigo $7^{\circ}$, essa definiu: "O ensino é livre à iniciativa privada, atendidas as seguintes condições: [...]". A finalidade dessa respectiva alteração seria a diversificação de oferta de ensino no país, imaginando uma possibilidade de competividade e redução de gastos com a educação.

Para entender a razão do interesse privado na educação, Gandin e Lima (2016, p.657) argumentam que

Ao partir do pressuposto de que a educação é permeada por lutas cotidianas em torno do discurso hegemônico, um campo de constituições políticas e ideológicas e um meio de reprodução e produção social, é compreensível que haja, por parte dos grupos hegemônicos, interesses pela educação e pela instituição escolar. Esses grupos veem a educação e a escola como campos no quais também há a possibilidade de tornarem seus discursos hegemônicos, de legitimarem seus ideais e de naturalizarem seus pressupostos.

Diante desse cenário, composto por várias facetas, dentre elas, privatizações; o ensino é tido como um produto de mercado, conforme se observa

Com essa compreensão de educação, são criadas as condições para que esse direito social se torne um serviço, um bem que pode ser acessado por meio do mercado, fazendo com que os interesses primeiros não sejam a qualidade da educação, mas os ganhos que a instituição privada terá a partir de sua venda, ou seja, a educação se torna objeto de lucro. (GUIMARÃES, GASPAROTTO, 2015, p. 136). 
Esse processo de mercantilização objetiva reduzir a participação do Estado em várias áreas, principalmente nas áreas de caráter social e, com isso, a educação passa a ter então incentivos à privatização, passando de direito social a uma mercadoria:

Dessa forma, é com a explosão do ensino superior brasileiro por meio do setor privado
tendo em vista a sua comercialização e lucratividade, que os programas: Fundo de Fi-
nanciamento ao Estudante do Ensino Superior (FIES) e Programa Universidade para
Todos (PROUNI), ganham corpo no mercado universitário juntamente com a modali-
dade de Ensino à Distância (EAD) os quais se inserem na reconfiguração da universida-
de brasileira dos dias atuais. (LOPES, VALLINA, SASSAKI, 2018, p. 37).

Nesse sentido, com essa abertura do Ensino Superior à iniciativa privada e sua consequente mercantilização, ainda foi possível identificar no meio empresarial, a formação de oligopólios educacionais, como por exemplo, os grupos, Estácio Participações S/A e Kroton Educacional $\mathrm{S} / \mathrm{A}$, os quais geram a concentração dos fornecedores dessa espécie de prestação de serviços, que é o ensino superior e, assim, Ball (2004, p.1114) completa "Em particular há um conjunto de marcas globais que estão surgindo e estão cada vez mais dominantes no mercado de Ensino Superior privado lucrativo."

A literatura jurídica descreve algumas situações em que um quadro econômico aparenta adquirir características de um oligopólio, por exemplo: a) a presença de um pequeno número de empresas; b) a prestação de serviços padronizados; c) o controle sobre os preços; e d) a criação de inúmeros obstáculos para o ingresso de novas empresas. (MASSO, 2015).

No Brasil, foram criadas redes de ensino por meio da compra ou fusão de Instituições de Ensino Superior (IES) e houve o investimento de capital nacional e estrangeiro na formação de tais oligopólios. O capital estrangeiro encontrou facilidade em adentrar no mercado nacional a partir do momento em que esses grupos empresariais optaram pela abertura de capitais na bolsa de valores.

Desde 2007, o processo de mercantilização do ensino superior brasileiro vem adquirindo novos contornos. Observa-se um forte movimento de compra e venda de IES no setor privado. Além das fusões, que têm formado gigantes da educação, as "empresas de ensino" agora abrem o capital na bolsa de valores, com promessa de expansão ainda mais intensa e incontrolável. (CHAVES, 2010, p. 491).

Contudo, ainda houve norma regulamentadora que viabilizou a criação ou fusão de IES, como o próprio art. 20, da Lei nº 9.394/96 (Lei de Diretrizes e Bases da Educação Nacional) que define tal possibilidade:

Art. 20. As instituições privadas de ensino se enquadrarão nas seguintes categorias:

I - particulares em sentido estrito, assim entendidas as que são instituídas e mantidas por uma ou mais pessoas físicas ou jurídicas de direito privado [...]

Dessa forma, além da abertura de capital na bolsa de valores, a própria LDB não criou óbices para o surgimento de oligopólios na prestação de serviços no Ensino Superior, pelo contrário, deixou expressa essa possibilidade nesse artigo da lei.

Nesse contexto, percebeu-se que o número de Universidades privadas cresceu, sendo que a procura pelo tema privatização/mercantilização está recorrente nas pesquisas para que se possa compreender o impacto que resultará nas políticas educacionais, conforme o estado do conhecimento aqui descrito e analisado. 


\section{CONSIDERAÇÕES FINAIS}

A produção desse estado do conhecimento sobre mercantilização/privatização da educação nos permitiu compreender em que condições estão as pesquisas na área, mas, sobretudo, identificar que esse é um tema que - em decorrência do número de pesquisas - configura o ensino superior no país e é diante desse cenário que outras pesquisas sobre esse nível de ensino precisam se orientar, no campo das políticas educacionais e do trabalho docente.

A realização do levantamento apontou que desde 1988 há estudos na área de educação sobre o fenômeno da mercantilização, em torno de várias temáticas, e realizados - predominantemente - na Região Sudeste. Cabe, portanto, cotejar esse fenômeno à formação humana, função e sentido finais da formação profissional em nível superior.

Para Saviani (2013), essa formação se dá no e pelo trabalho, ação que antecipa uma finalidade, e é próprio do ser humano imbricando com o sentido mesmo da educação. Nas palavras do autor

Considerando que é o trabalho que define a essência humana, podemos considerar que está aí a referência ontológica para se compreender e reconhecer a educação como formação humana. O homem se constitui como homem, ou seja, se forma homem no e pelo trabalho. (SAVIANI, 2013, p. 195).

Nessa linha, o mesmo autor, acompanhado de Newton Duarte, avança nessa compreensão defendendo que "se a educação é uma atividade específica dos seres humanos, se ela coincide com o processo de formação humana, isso significa que o educador digno desse nome deverá ser um profundo conhecedor do homem". (SAVIANI e DUARTE, 2010, p.423).

Alertamos, ao final do estudo, que há uma relação antagônica entre a concepção de formação humana defendida por Saviani e Duarte - da qual compartilhamos - com a mercantilização da educação superior. Enquanto a primeira argumenta acerca do trabalho - ação intencional humana - e que os processos educativos devem se dar por meio de algo/alguém profundo conhecedor desses fundamentos, a mercantilização advoga a precarização e exploração da vida humana com base nos preceitos de eficiência, eficácia e produtividade. Do debate filosófico da formação humana - omnilateralidade - é preciso envolver o campo político de modo a resistir e denunciar que não há conciliação possível entre gente e lucro, formação humana e reestruturação produtiva e acumulação do capital: a que servem e servirão as instituições de ensino superior?

Do ponto de vista da pesquisa acadêmica, há um importante papel desses estudos no sentido de apontar esse percurso de aprofundamento da mercantilização do ensino superior e desvelar os impactos desse movimento para esse nível de ensino, especialmente no que se refere ao esvaziamento da formação humana, própria e essência, como já dito, da educação, em todos os níveis de ensino.

\section{COMMERCIALIZATION VERSUS HUMAN FORMATION IN HIGHER EDUCATION: NOTES ON ACADEMIC PRODUCTION}

ABSTRACT: Considering the expansion of Higher Education in Brazil in the last twenty years and the integral formation as a basic principle of all educational levels, this article brings and analyzes dissertations and theses produced in the area of Education on the phenomenon of the commercialization of Higher Education. Through the state of knowledge carried out at the Bank of theses and dissertations of CAPES, by using - primarily - the terms commercialization and privatization and, in view of the data collected, we can highlight the number of surveys 
available at that bank between 1988 and October 2019, the distribution by region in the country and the main topics discussed. Finally, it collates the phenomenon of the commercialization of higher education to the principles of human formation and problematizes the need to expand these studies in order to reveal the impact of this process at this level of education.

KEYWORDS: Higher Education. Commercialization. Human Formation. State of knowledge.

\section{REFERENCIAS}

AGAPITO, Ana Paula Ferreira. Ensino Superior no Brasil: expansão e mercantilização na contemporaneidade. Temporalis, Brasília (DF), ano 16, n. 32, jul/dez. 2016. Disponível em: http:// periodicos.ufes.br/temporalis/article/view/14064. Acesso: 02/dez/2019.

BALL, Stephen J. Performatividade, privatização e o pós-Estado do bem-estar. Educação e Sociedade, v. 25, n. 89, p. 1105-1126, set/dez 2004.

BITTAR, Mariluce; Stapani Ruas, Claudia Mara. Expansão da Educação Superior no Brasil e a formação dos oligopólios - hegemonia do privado mercantil. EccoS Revista Científica, vol. 29, 2012, pg. 115-133, São Paulo: Universidade Nove de Julho.

BRASIL. Lei 9.394, de 20 de dezembro de 1996 - Lei de Diretrizes e Bases da Educação Nacional. Disponível em: < http://www.planalto.gov.br/ccivil_03/leis/L9394.htm >. Acesso em: 12/dez/2019.

BRESSER PEREIRA, Luiz Carlos, Uma nova gestão para um novo Estado: liberal, social e republicano.

Revista do Servidor Público. Brasília, v. 52, n. 1, jan/mar 2001.

CAPES. Coordenação de Aperfeiçoamento de Pessoal de Nível Superior. Serviços: Banco de teses e dissertações. Disponível em: < https://catalogodeteses.capes.gov.br/catalogo-teses/\#!/>. Acesso em: 29/out/2019.

CHAVES, Vera Lúcia Jacob. Expansão da privatização/mercantilização do ensino superior brasileiro: a formação dos oligopólios. EDUC. SOC., Campinas, v. 31, n. 111, p. 481-500, abr.-jun. 2010. Disponível em: http://www.scielo.br/scielo.php?pid=S0101-3302010000200010\&script=sci_abstract\&tlng=pt. Acesso: 03/dez/2019.

FRIGOTTO, Gaudêncio and CIAVATTA, Maria. Educação básica no Brasil na década de 1990: subordinação ativa e consentida à lógica do mercado. Educ. Soc. [online]. 2003, vol.24, n.82, pp.93130. ISSN 0101-7330. http://dx.doi.org/10.1590/S0101-73302003000100005. Disponível em http:// www.scielo.br/scielo.php?pid=S0101-73302003000100005\&script=sci_abstract\&tlng=pt. Acesso em 20/dez/2018.

GANDIN, Luís Armando; LIMA, Iana Gomes de. A perspectiva de Michael Apple para os estudos das políticas educacionais. Educ. Pesqui., São Paulo, v. 42, n. 3, p. 651-664, Sept. 2016 Disponível em: $<$ http://www.scielo.br/scielo.php?script=sci_arttext\&pid=S1517-97022016000300651\&lng=en\&nrm=i so>. Acesso em: 01/out/2018.

GUIMARÃES, Gleny Terezinha Duro, GASPAROTTO, Geovana Prante. Política de Educação Mercantilizada: quais os seus rumos?Textos \& Contextos, Porto Alegre, v. 14, n. 1, p. 132 - 144, jan./ jun. 2015. Disponível em: http://repositorio.pucrs.br/dspace/bitstream/10923/7963/2/Politica_de_ Educacao_Mercantilizada_quais_os_seus_rumos_Commodified_education_what_are_the_directions. pdf. Acesso:03/dez/2019.

INSTITUTO NACIONAL DE ESTUDOS E PESQUISAS EDUCACIONAIS ANÍSIO TEIXEIRA. Sinopse Estatística da Educação Superior 2017. Brasília: Inep, 2018. Disponível em: <http://portal. inep.gov.br/basica-censo-escolar-sinopse-sinopse> Acesso em: 29 out. 2019.

LOPES, Maria Gracileide Alberto, VALLINA Kátia, SASSAKI, Yoshiko. A mercantilização do ensino superior no contexto atual: considerações para o debate. Interfaces Científicas - Educação, Aracaju, V.6, N.2, p. 29 - 44, fevereiro - 2018. Disponível em: https://periodicos.set.edu.br/index.php/educacao. Acesso: 03/jan/2019.

MASSO, Fabiano Del. Direito econômico. $3^{\mathrm{a}}$ ed. São Paulo: Método, 2015.

MOROSINI, Marilia Costa. Estado de conhecimento e questões do campo científico. Educação. Santa 
Maria. v. 40. n. 1.p. 101-116 .jan./abr. 2015. Disponível em: https://periodicos.ufsm.br/reveducacao/ article/view/15822/pdf. Acesso: 03/mai/2018.

OLIVEIRA, Romualdo Portela de. A transformação da educação em mercadoria no Brasil. Educ. Soc., Campinas, vol. 30, n. 108, p. 739-760, out. 2009. Disponível em: https://www.scielo.br/pdf/es/v30n108/ a0630108.pdf. Acesso: 01/abr/2020.

PERONI, Vera Maria Vidal. As relações entre o público e o privado nas políticas educacionais no contexto da terceira via. Currículo sem Fronteiras, v. 13, n. 2, p. 234-255, maio/ago. 2013.

ROMANOWSKI, Joana Paulin; ENS, Romilda Teodora. As pesquisas denominadas do tipo "estado da arte" em educação. Diálogo Educ., Curitiba, v. 6, n.19, p.37-50, set./dez. 2006. Disponível em https:// periodicos.pucpr.br/index.php/dialogoeducacional/article/view/24176/22872 Acesso: 03/mai/2018. SAVIANI, Dermeval. Debate sobre as relações entre educação, formação humana e ontologia a partir do método dialético. Perspectiva, Florianópolis, v. 31 n. 1, 185-209, jan./abr. 2013. Disponível em: https:// periodicos.ufsc.br/index.php/perspectiva/article/viewFile/2175-795X.2013v31n1p185/25654. Acesso em: $01 /$ fev/2020.

SAVIANI, Dermeval e DUARTE, Newton. A formação humana na perspectiva histórico-ontológica. Revista Brasileira de Educação.v. 15 n. 45 set./dez. 2010. Disponível em: https://www.scielo.br/pdf/ rbedu/v15n45/02. Acesso: 01/fev/2020.

SERAFIM, Milena Pavan. O processo de mercantilização das Instituições de educação superior: um panorama do debate nos EUA, na Europa e na América Latina. Avaliação, Campinas; Sorocaba, SP, v. 16, n. 2, p. 241-265, jul. 2011. Disponível em https://www.scielo.br/pdf/aval/v16n2/a02v16n2.pdf. Acesso: 01/abr/2020. 